\title{
Willingness to Pay for Environmentally Friendly Products among Low-Income Households along Coastal Peninsular Malaysia
}

\author{
Abdullah Al Mamun ${ }^{1, *(\mathbb{D})}$, Syed Ali Fazal ${ }^{2} \mathbb{1}^{\circ}$, Ghazali Bin Ahmad ${ }^{3}$, Mohd Rafi Bin Yaacob ${ }^{2}$ and \\ Mohd. Rosli Mohamad ${ }^{2}$ \\ 1 Global Entrepreneurship Research and Innovation Centre (GERIC), Universiti Malaysia Kelantan, \\ 16100 Kota Bharu, Kelantan, Malaysia \\ 2 Faculty of Entrepreneurship and Business, Universiti Malaysia Kelantan, 16100 Kota Bharu, Kelantan, \\ Malaysia; syedfazal971@hotmail.com (S.A.F.); rafi@umk.edu.my (M.R.B.Y.); mrosli@umk.edu.my (M.R.M.) \\ 3 Faculty of Hospitality, Tourism and Wellness, Universiti Malaysia Kelantan, 16100 Kota Bharu, Kelantan, \\ Malaysia; ghazali@umk.edu.my \\ * Correspondence: abdullah.a@umk.edu.my or mamun7793@gmail.com; Tel.: +60-13-3003630
}

Received: 5 April 2018; Accepted: 23 April 2018; Published: 24 April 2018

check for updates

\begin{abstract}
In an attempt to promote the mass consumption of environmentally friendly products in Malaysia, this study presents an investigation of the effects of several selected factors upon willingness to pay and purchase behavior of environmental-friendly products. This study employed a cross-sectional design, in which quantitative data were gathered from a total of 380 low-income household heads from 38 coastal districts in Peninsular Malaysia. The outcomes of this study revealed the positively significant effects of eco-literacy and environmental concern upon attitudes towards environmental-friendly products; normative beliefs and perceived behavioral control on willingness to pay for environmental-friendly products; as well as willingness to pay for environmental-friendly products and perceived behavioral control on payment behavior for environmental-friendly products, among low-income households in coastal Peninsular Malaysia. Programs and policies should therefore focus on promoting environmental awareness and knowledge concerning the relative advantages that are expected to improve willingness among consumers to pay for environmentally friendly products.
\end{abstract}

Keywords: willingness to pay; environmental-friendly products; theory of planned behavior

\section{Introduction}

Several significant factors, such as climate change, waste generation, air pollution, and natural disasters, have substantially changed the world environment, hence impacting all living organisms, along with the social and economic status of people [1]. The rapid growth of global economies is to be blamed for the escalating trend of consumerism worldwide, which, in turn, has caused over utilization of natural resources, thus leading towards severe environmental degradation [1,2]. Within the context of Malaysia, the rapidly rising population, coupled with accelerated industrialization and urbanization, has led to some major environmental issues, such as increment in solid waste and greenhouse gas emissions as byproducts $[3,4]$. Concerns pertaining to the deteriorating natural environment have compelled both organizations and consumers to minimize damages inflicted towards the environment [5]. Out of such motivation of altruism, consumers have begun to progressively pay more attention towards environmentally friendly products as a key effort to preserve the environment [6].

Environmentally friendly or green products are ecological products that do not pollute the environment and have less negative impact over the environment than their traditional alternatives [2]. 
Besides, Mishra and Sharma [7] asserted that 'green products', as authentically grown, reusable, and recyclable consumables containing natural and recycled ingredients protect and revive the natural environment by conserving energy resources and minimizing pollution, waste, and toxic agents. Chen and Chai [8] contended that green products contain more environmentally sound content and packaging, thus reducing their environmental impact. Qader and Zainuddin [9] claimed that unlike conventional goods, green products do not deplore natural resources and can be recycled. In terms of market demand, Maichum et al. [1] stated that green products that produced the following sustainable development principles are among the most widely used products globally due to the environmental benefits embedded in them, such as safety for purchasers (health) and superior quality. Particularly within the local context, Mei et al. [2] noted that an escalated demand for environmentally friendly products exists within the Malaysian market, hence portraying the subsistence of green consumers within the country who are willing to support green consumerism.

Lanzini, Testa, and Iraldo [10] stressed that willingness among consumers to pay for green products is one of the key driving factors for companies to implement the aspect of eco-friendliness in their products and services. On this, Ha and Janda [11], in elaborating the reasons of limited success of green products in the mass market, noted that discrepancies between consumers' perceptions about environmental issues, their willingness to pay, and their actual purchase behavior are responsible for the inconsistent trend of purchasing green products, hence highlighting the importance of understanding perceptions among consumers towards environmental issues and their willingness to pay for consuming green products. Within the local context, the issue highlighted by Ha and Janda [11] can be translated as a lack of attention towards low-income communities, which apparently represent the mass market in Malaysia. Al-Mamun et al. [12] noted that economic activity amidst the low-income sector plays a significant role in Malaysia, primarily because around 1.3 million individuals $(9.7 \%$ of the total workforce) are actively engaged in micro-economic operations and informal businesses. As portrayed in the existing literature, consumers may avoid environmental-friendly products, perhaps due to their socio-economic characteristics [13] or communal issues [14]. This indicates that it is highly significant and timely to identify consumers' perceptions and intentions towards the adoption of environmental-friendly products, especially from the stance of low-income households in these rapidly emerging economies, such as that experienced in Malaysia.

The growing significance of green consumption and the increasing purchase of less polluting products that reflect environmentally friendly behavior have turned the topic into a popular research issue among scholars [6]. However, Mei et al. [2] specifically highlighted that in comparison to Western counterparts, studies pertaining to green purchasing are relatively scant among Asian countries. In a similar vein, Maichum et al. [1] echoed that information regarding purchase intentions for environmentally friendly products among consumers in developing nations is still inadequate. Additionally, findings from prior, related studies appear to be in disagreement, therefore indicating the pressing need for deeper research penetration into the subject matter. This study, in order to bridge a gap in the body of knowledge, investigated the influential factors of willingness to pay and payment behavior for green products among low-income households residing at Coastal Peninsular Malaysia under the premise of an extended Theory of Planned Behavior framework [15], which appears to be a prominent choice in explaining the pro-environmental behavior amongst the existing literature [6,16-27].

\section{Literature Review}

\subsection{Theory of Planned Behavior (TPB)}

The Theory of Planned Behavior (TPB) has been reckoned to be one of the most influential and fundamental theories that explain behavioral intentions, and it has been extensively employed in past research to look into environmentally friendly consumption behavior $[6,16]$. The TPB hypothesizes that one's behavior could be determined by behavioral intentions that can be predicted by certain 
socio-cognitive factors, such as attitudes, subjective norms, and perceived behavior control [15]. In fact, Ajzen [15] asserted that favorable or unfavorable attitudes towards a particular behavior are caused by one's behavioral beliefs; subjective norms result from normative beliefs and personal moral norms, while perceived behavioral control originates from control related beliefs. Collectively, attitudes towards behavior, subjective norms, and perceived behavioral control influence the formation of a behavioral intention, which determines the actual behavior [15].

Although the TPB reflects robust explanatory power in behavioral decisions, its integrity is yet questioned [28]. Based on the review of relevant literature, the exploration of additional constructs that may enhance the predictive power of the TPB has revealed that vast studies did deploy the TPB to investigate the factors of purchase intention for environmental-friendly products and services, such as customers' intentions to visit green hotel [17-19,22], to engage and willingness to pay premium prices for ecotourism [21], to purchase organic personal care products [20], to be willing to purchase organic foods [23-25], to be willing to pay for green electricity [26], and to select eco-friendly restaurants [27].

In particular, Chen and Tung [17] extended the TPB model by integrating the aspects of environmental concern and perceived moral obligation to predict consumers' intentions to visit green hotels. The outcomes of the study revealed that consumers' environmental concern did exert a positive influence on their attitudes towards green hotels, subjective norms, and perceived behavioral control (i.e., the antecedents of the TPB model), as well as their perceived moral obligation, which, in turn, influenced their intention to visit green hotels. Meanwhile, Kim and Chung [20] contributed towards the TPB by amalgamating health consciousness, environmental consciousness, and appearance consciousness into the original model as additional antecedents of consumers' attitudes towards buying organic skin/hair care products. In a similar attempt, Tarkiainen and Sundqvist [24] improvised the TPB to better fit their data by integrating health consciousness and subjective norms as predictors of attitudes towards buying organic food. Nevertheless, these studies appeared to have disregarded the impacts of other domain-specific and significant environment-related constructs, for instance, eco-literacy [28] or environmental concern [17], especially within a single extended TPB framework.

Environmental concern has been acknowledged as a significant determinant of environmental behavior that is predicted by the attitude displayed by consumers towards a specific behavior [1] On the other hand, eco-literacy, due to consumers' lack of environmental knowledge, could cause an attitude-behavioral gap, resulting in inadequate intention towards purchasing green products [1]. Furthermore, in terms of subjective norms, as a combination of normative beliefs and personal norms, it is presumed that in a collectivist society, such as Malaysia (being an Asian country), certain individual traits, such as personal moral norms, values, or obligation (significant aspects in the individualistic western nations), do not contribute much to influencing intention and adoption of green products $[14,29]$. As such, this study embedded eco-literacy and environmental concern in the original TPB model as antecedents of consumers' attitudes towards environmentally friendly products, along with normative beliefs (as an independent variable) and perceived behavioral control, in order to determine willingness to pay (intention) and payment behavior for green products from the stance of low-income household heads in Malaysia. This work also appears to extend the application and to broaden the predictive power of the adapted TPB framework, particularly from the stance of green purchase intention behavior.

\subsection{Attitudes towards Environmentally Friendly Products}

Attitude denotes one's negative or positive evaluation of self-performance regarding a particular behavior [15]. Within the studied context, attitudes towards environmentally friendly products are perceived as the degree to which performance of green purchase behavior is negatively or positively valued by individuals [6]. Based on TPB, one's attitude is a strong predictor of behavioral intention [15]. Within the context of pro-environmentalism, Maichum et al. [1] found that consumer attitude can significantly have a positive effect upon their purchase intention for environmentally friendly products. In terms of green consumption, $\mathrm{Wu}$ and Chen [16] discovered that attitude exhibited a significantly 
positive impact on consumers' behavioral intentions. Meanwhile, from the stance of Malaysian consumers, Mei et al. [2] revealed that a significant antecedent that affects green purchase intention is environmental attitude. In a prior study, Tsen, Phang, Hasan, and Buncha [30] had similarly observed consumers' attitudes in Kota Kinabalu, Malaysia to be the most consistent explanatory factor in predicting willingness to pay for green products. Hence, after weighing in both theory and existing literature, the following hypothesis is drawn:

Hypothesis 1 (H1). Attitudes Towards Environmental-Friendly Products Have a Significantly Positive Effect on Willingness to Pay for Environmentally Friendly Products among Low-Income Households in Coastal Peninsular Malaysia.

\subsubsection{Eco-Literacy}

Ecological knowledge or eco-literacy is defined as one's ability to identify ecological symbols, concepts, behavior, etc. [31]. In general, knowledge reflects the characteristic that influences all phases in one's decision-making process [2], which may form either positive or negative attitudes towards a certain behavior. In an attempt to promote pro-environmental behavior, consumers will need to be educated in order to comprehend the general impact of a product on the environment, along with the knowledge of the product itself if it is produced in an environmental-friendly manner. According to Laroche et al. [31], one's knowledge about the environment or eco-literacy enlightens one with knowledge about action strategies and issues, aside from aiding to shape attitudes and intentions through the belief system. This would eventually lead towards the practical aspects of the knowledge variable as the significant leverage points, in which marketers and agencies can influence pro-environmental behavior, are emphasized. Empirically, Cheah and Phau [32] have highlighted that the level of eco-literacy is significantly correlated with consumers' attitudes and behavioral tendencies, hence implying that awareness amongst consumers about the environment is indeed crucial to forming a favorable mindset towards environmental-friendly products. Particularly within the Malaysian context, a recent study revealed that its students possess high levels of environmental knowledge, which nurtures positive attitudes towards environmental issues [33]. From the discussion above, the notion upheld in the likelihood model [34], denoting the situation-specific cognition of an individual, was weighed to establish that eco-literacy can process information in central route through a substantial amount of environmental cognition, which is thus positively linked with positive attitude towards environmental-friendly products.

Hypothesis 2 (H2). Eco-Literacy Has a Significantly Positive Effect on Attitudes Towards Environmentally Friendly Products among Low-Income Households in Coastal Peninsular Malaysia.

\subsubsection{Environmental Concern}

Environmental concern is perceived as the evaluation of one's attitude towards facts, his or her own behavior, or the behavior of others that has consequences towards the environment [28]. According to Maichum et al. [1], consumers can translate their environmental awareness into staunch attitude to purchase environmental-friendly products. Kai and Haokai [28] asserted that environmental concerns have to be treated as evaluation of, or an attitude towards, facts, one's own behavior, or others' behavior with consequences for the environment. Furthermore, it has been highlighted that consumers with higher levels of environmental concerns are more likely to exert environmental-friendly consumption. In fact, Yadav and Pathak [35] have expressed in their study that environmental concerns are definitely essential in predicting environmental attitudes, which could contribute towards consumers' decision-making processes, such as purchasing eco-friendly products. Furthermore, Maichum et al. [1] empirically demonstrated that environmental concerns have a significantly positive impact upon one's attitude towards environmentally friendly products. In a similar vein, Kai and Haokai [28] asserted that consumers' environmental concern could stimulate 
green consumption by means of influencing behavioral attitudes and intentions. Mostafa [36] also reported that environmental concerns might have a positive impact upon individuals' attitudes towards environmental-friendly products, which, in turn, could affect their environmentally friendly purchase intentions. As elaborated previously, it could be perceived that, in accordance with the notion emphasized in the likelihood model [34], consumers become more concerned about the environment upon consuming higher levels of green energy, in comparison to the general population [35], thus indicating that environmental concern processes information in central route with massive environmental cognition. This suggests that environmental concern is positively associated with positive attitude towards environmentally friendly products. With that said, the following hypothesis is proposed.

Hypothesis 3 (H3). Environmental Concern Has a Significantly Positive Effect on Attitudes Towards Environmental-Friendly Products among Low-Income Households in Coastal Peninsular Malaysia.

\subsection{Mediating Effect of Attitudes towards Environmentally Friendly Products}

As this study hypothesized significantly positive effects of eco-literacy and environmental concern on attitudes towards environmentally friendly products, along with the positively significant impact of attitudes towards environmentally friendly products on consumers' willingness to pay for environmentally friendly products, this study investigated the mediating effect of attitudes towards environmentally friendly products on the relationships of eco-literacy and environmental concern with consumers' willingness to pay for environmentally friendly products. Moreover, theoretically, the TPB propounded that the available information (in the form of attitudes towards environmental-friendly products) mediates the effects of both personal and environmental factors (eco-literacy, and environmental concern) on intention (willingness to pay) and behavior (payment behavior) among fully functioning individuals [15]. Furthermore, this study incorporated the dimensions of eco-literacy and environmental concern into the TPB, with the expectation of increasing the predictive power of the original model [37], wherein the new constructs have been estimated to exhibit an indirect impact upon intention, which is mediated through the components of the original model (attitude) [38]. Therefore, following Maichum et al. [1] and Kai and Haokai [28], this study hypothesized the following:

Hypothesis 4 (H4). Attitudes Towards Environmental-Friendly Products Mediates the Effect of Eco-Literacy on Willingness to Pay for Environmental-Friendly Products among Low-Income Households in Coastal Peninsular Malaysia.

Hypothesis 5 (H5). Attitudes Towards Environmental-Friendly Products Mediates the Effect of Environmental Concern on Willingness to Pay for Environmental-Friendly Products among Low-Income Households in Coastal Peninsular Malaysia.

\subsection{Normative Beliefs}

Normative belief reflects one's perception of the extent to which he or she should yield towards social pressure [39]. Normative beliefs can be translated as the expectations of significant others, such as family, friends, relatives, colleagues, and others, which are assumed to govern perceived social pressure over individuals [6]. In accordance with the TPB, normative beliefs may be perceived as the social pressure that significantly influences one's behavioral intentions [15]. According to Rhodes and Courneya [40], normative pressure has an impact upon the intention of individuals (belonging to a group) to perform a certain behavior. Meanwhile, Wu and Chen [16] noted that one's strong belief in social norms can guarantee specific behavior in conforming to social expectations, thus establishing normative beliefs as an important factor in exerting influence upon an individual's behavior. 
As for pro-environmental behavior, Oskamp et al. [41] revealed that friends and neighbors who practiced recycling significantly influenced recycling behavior among individuals, thus signifying that peer influence, as a form of normative pressure, appears to be a significant determinant in one's decision to recycle. In the case of green purchasing, Kai and Haokai [28] promulgated that one's decision related to green behavior largely depends on the perceptions of family, friends, and significant others towards an individual. Particularly within the context of Malaysia, Mei et al. [2], found that one of the most significant antecedents that had an effect upon green purchase intention was peer pressure. Thus, based on both theory and existing literature, the following hypothesis is drawn:

Hypothesis 6 (H6). Normative Beliefs Have a Significantly Positive Effect on Willingness to Pay for Environmental-Friendly Products among Low-Income Households in Coastal Peninsular Malaysia.

\subsection{Perceived Behavioral Control}

Perceived behavior control is conceptualized as the acquisition of opportunities and resources, such as specific skills, cooperation of others, etc., which is perceived to facilitate one in performing a specific behavior [6]. The TPB conveys that developing perceived behavioral control prior to generating behavioral intention is essential [15]. Empirically, Wang et al. [29] and Afroz et al. [3] discovered that consumers' perceived behavioral control significantly influenced adoption intention towards green vehicles. Furthermore, within the context of green purchasing, Maichum et al. [1] revealed that consumers' perceived behavioral control has a significantly positive effect upon purchase intention towards environmental-friendly products. Interestingly, some scholars have further argued that in the context of non-volitional behavior, wherein behaviors could pose difficulties in execution, perceived behavioral control, in terms of presence of restrictions, limitation of skills, chances, or external conditions, may significantly predict actual behavior with behavioral intention $[15,28,42,43]$. Furthermore, $\mathrm{Wu}$ and Chen [16] provided empirical evidence that behavior control does have a significantly positive impact upon both consumers' behavioral intention and actual behavior. Therefore, based on both theory and existing literature, the following hypotheses are proposed:

Hypothesis 7 (H7). Perceived Behavioral Control Has a Significantly Positive Effect on Willingness to Pay for Environmentally Friendly Products among Low-Income Households in Coastal Peninsular Malaysia.

Hypothesis 8 (H8). Perceived Behavioral Control Has a Significantly Positive Effect on Payment Behavior for Environmental-Friendly Products among Low-Income Households in Coastal Peninsular Malaysia.

\subsection{Willingness to Pay for Environmentally Friendly Products}

Intentions represent an individual's conscious motivation or willingness to make an effort to engage in a particular behavior $[15,16,28,44]$. Within the present context, consumers' willingness to pay for environmentally friendly products could be perceived as a green purchase intention that reflects an individual's consideration of less pollution and readiness to perform green purchase behavior $[6,10]$. Theoretically, the TPB suggests that the closest determinant of volitional behavior is one's intention to engage in a specific behavior $[15,28]$. Ajzen [15] claimed that stronger intention indicates higher possibility of performing a particular behavior. The existing empirical evidence also seems to suggest that, in general, intentions significantly predict behavior $[45,46]$. Particularly, within the context of green consumption, empirical evidence reveals that behavioral intention positively influences actual behavior $[16,36]$. Hence, deducing from theory and existing literature, the following hypothesis is drawn:

Hypothesis 9 (H9). Willingness to Pay for Environmental-Friendly Products Has a Significantly Positive Effect on Payment Behavior for Environmentally Friendly Products among Low-Income Households in Coastal Peninsular Malaysia. 


\subsection{Mediating Effect of Willingness to Pay for Environmentally Friendly Products}

As this work hypothesized the effect of attitude upon environmental-friendly products, normative beliefs, and perceived behavioral control on willingness to pay, along with the effect of consumers' willingness to pay on payment behavior, this study rationally expects willingness to mediate the effect of attitudes towards environmentally friendly products, normative beliefs, and perceived behavioral control on payment behavior for environmentally friendly products. Theoretically, the TPB also supports that intention (willingness to pay) should completely mediate the effects of constructs that serve as predictors (i.e., attitudes towards environmentally friendly products, normative beliefs, and perceived behavioral control) on later action, i.e., behavior (payment behavior) [15]. Empirically, Wu and Chen [16] showed that the effect of TPB antecedents on actual behavior is mediated by behavioral intentions in terms of green consumption. Hence, considering the discussion above, the following is hypothesized:

Hypothesis 10 (H10). Willingness to Pay for Environmentally Friendly Products Mediates the Effect of Attitudes Towards Environmental-Friendly Products on Payment Behavior for Environmental-Friendly Products among Low-Income Households in Coastal Peninsular Malaysia.

Hypothesis 11 (H11). Willingness to Pay for Environmentally Friendly Products Mediates the Effect of Normative Beliefs on Payment Behavior for Environmentally Friendly Products among Low-Income Households in Coastal Peninsular Malaysia.

Hypothesis 12 (H12). Willingness to Pay for Environmentally Friendly Products Mediates the Effect of Perceived Behavioral Control on Payment Behavior for Environmentally Friendly Products among Low-Income Households in Coastal Peninsular Malaysia.

\section{Research Methodology}

This study employed a cross-sectional design and gathered quantitative data via structured interview to determine the effects of selected variables on willingness and behavior towards payment for environmental-friendly products among low-income households in Coastal Peninsular Malaysia. The study population is comprised of the low-income households from Coastal Peninsular Malaysia with a net income below RM2000, as retrieved from the Prime Minister's Department [47]. The Implementation and Coordination Unit of the Prime Minister's Department (ICU-JPM), Malaysia had prepared a database of low-income households in Malaysia with specific information, including name, address, and contact details. After obtaining formal request from researchers, the ICU-JPM provided a list of 500 low-income household heads living in 36 coastal districts from 10 states in Peninsular Malaysia. These 500 low-income households were selected from a database that had information regarding 78,118 low-income households via random sampling method, from 38 coastal districts in Peninsular Malaysia. Prior to data collection, the data collection team contacted the selected household heads to brief them about the survey and set appointment for interview. Complete data were collected in July and August 2017 from a total of 380 respondents, who allowed the researchers to visit their premises and to gather data via structured interview. Among them, 40 were from Johor ( 8 from Pontian, 9 each from Johor Bharu and Batu Pahat, and 7 each from Muar and Mersing), 35 from Pahang (20 from Pekan and 15 from Rompin), 36 from Kedah (10 from Kota Setar, and 13 each from Kuala Muda and Yan), 37 from Kelantan (9 from Bachok, 11 from Kota Bharu, 10 from Pasir Puteh, and 7 from Tumpat), 35 from Perlis (15 each from Kayang, Kuala Perlis, and Sanglang), 38 from Terengganu (6 each from Kuala Terengganu, Setiu, Kuala Nerus, Besut, and Marang, and 8 from Kemaman), 39 from Penang (7 from Seberang Prai Selatan, 8 from Utara, 5 from Tengah, 10 from Timor Laut, and 9 from Barat Daya), 40 from Selangor (10 each from Sabak Bernam, Kuala Selangor, Klang, as well as Kuala Langat and Sepang), 41 from Perak (11 each from Hilir Perak and Larut Matang \& Selama, 
10 from Manjung, and 9 from Kerian), and lastly, 39 respondents from Melaka Tengah, from the state of Melaka.

\subsection{Sample Size}

The sample size for this study was determined via G-Power version 3.1. Based on the power of 0.95 (which exceeds 0.80 , as required in social and behavioral science research) with an effect size of 0.15 , this study required a sample size of 146 to test the model that comprised of 6 predictors. Besides, Reinartz, Haenlein, and Henseler [48] suggested a minimum threshold of 100 samples for PLS-SEM. Hence, in order to avoid any complication that may arise from a small sample size, this study gathered data from 380 low-income household heads living in 36 districts from 10 states in Coastal Peninsular Malaysia.

\subsection{Research Instrument}

The questionnaire was designed by using simple and unbiased terms so as to ease comprehension of questions among the respondents in order to ensure that answers were provided based on their own perceptions. The questions were adapted from prior studies with minor alterations where required. More details on each section, for instance, what is measured and from whom the questions were adapted, are provided in the following. The items used to measure eco-literacy were adopted from Maichum et al. [1] and Mostafa [36]. As for environmental concern, the items were adopted from Cheung, Lau, and Lam [49]. Meanwhile, items that measured attitudes towards environmentally friendly products were adopted from Ha and Janda [11] and Maichum et al. [1], normative beliefs from $\mathrm{Wu}$ and Chen [16], and perceived behavior control from Maichum et al. [1]. Lastly, items for willingness to pay for environmental-friendly products were adopted from Ha and Janda [11] and Afroz et al. [3], whereas items regarding payment behavior for environmentally friendly products were adopted from Walton and Austin [50], Sánchez, López-Mosquera, and Lera-López [51], as well as Osman et al. [4]. Furthermore, as recommended by Podsakoff et al. [52], this study adopted the seven-point Likert scale (1 to 7 , from 'strongly disagree' to 'strongly agree') for dependent variable and five-point Likert scale ( 1 to 5 , from 'strongly disagree' to 'strongly agree') for independent variables.

\subsection{Common Method Variance (CMV)}

As a procedural remedy to reduce the effect of common method bias, apart from carefully constructing the items, this study also 'informed the respondent that the responses are evaluated anonymously and there is no right or wrong answer' at the time the data were collected [52]. As for statistical remedy, this study adopted the Harman's [53] one-factor test, in adherence to Podsakoff et al. [52], in which one fixed factor extracted from all principal constructs is expected to explain less than 50 percent of the variance. As a result, the outcomes showed that one component explained 44.67 percent of the variance, which appears to be less than the maximum threshold of 50 percent. Additionally, the correlation between the constructs that scored more than 0.9 is considered as an indicator of common method bias [54]. As for this study, the highest correlation between the constructs was 0.671 (between eco-literacy and normative beliefs), which advocated a lack of common method bias in the gathered data.

\subsection{Multivariate Normality}

This study examined multivariate normality by using the Web Power online tool. The Web Power was employed to calculate Mardia's multivariate skewness, kurtosis coefficients, and $p$-values, which indicated that the $p$-value of Mardia's multivariate skewness and kurtosis coefficients was less than 0.05 , thus confirming the occurrence of multivariate non-normality. 


\subsection{Data Analysis Method}

PLS-SEM refers to a causal modeling approach that maximizes the explained variance of the dependent latent constructs [55]. Hence, due to the exploratory nature of this study, along with its non-normality issue, this study employed the variance-based structural equation modeling via partial least squares (PLS-SEM) estimation to maximize elaboration of variance among the dependent constructs via structural equation modelling method. The outcomes of this analysis reflect those recommended by Hair, Ringle, and Sarstedt [56] for PLS modeling, which are inclusive of indicator reliability, internal consistency reliability, convergent validity, discriminant validity, average variance extracted, effect size, path coefficient estimates, and predictive relevance.

\section{Summary of Findings}

\subsection{Demographic Characteristics}

The data for this study was collected from randomly selected 380 low-income household heads from coastal Peninsular Malaysia. Among them, 191 (50.3\%) were males, while the remaining 189 $(49.7 \%)$ were females. A total of $80(22.9 \%)$ respondents were aged between 21 and 30 years old, 88 each $(23.2 \%)$ were from 31 to 40 years old and 51 to 50 years old, while the remaining $42(11 \%)$ respondents were either below 21 or above 60 years old. As for education level, $196(51.6 \%)$ had completed secondary school, followed by 64 (16.8) who completed primary school level, $54(14.2 \%)$ held diploma, and 27 (7.1\%) had bachelor's degree and above, whereas 39 (10.3\%) never attended formal school. As for employment status at the time of study, a total of 374 (98.4\%) reported being 'gainfully employed', while the remaining $6(1.6 \%)$ were unemployed. Lastly, regarding income sources, only two households reported that they did not have any income; $232(61.1 \%)$ households had only one source of income, followed by $121(31.8 \%)$ with two sources of income, and the remaining $25(6.6 \%)$ had three or more sources of income.

\subsection{Reliability and Validity}

Table 1 presents the descriptive statistics, including number of items, as well as mean and standard deviation values of all variables (i.e., eco-literacy, environmental concern, attitudes towards environmentally friendly products, normative beliefs, perceived behavioral control, willingness to pay for environmental-friendly products, and payment behavior for environmentally friendly products). The Cronbach's alpha (conservative measure of internal consistency reliability) values, as displayed in Table 1 , show that all constructs have values exceeding 0.9 , hence indicating that all the items used are indeed reliable. This study also adopted a different measure of internal consistency reliability, known as 'composite reliability'. The cutoff value for composite reliability is 0.7 [55]. As tabulated in Table 1, the composite reliability values for all constructs exceed 0.9 , thus signifying the reliability of the items used to measure the constructs. In addition, the Dillon-Goldstein rho values for all constructs are more than 0.9 , re-affirming the reliability aspect of the items. Finally, in order to achieve convergent validity, the average variance extracted (AVE) value should be higher than 0.50 . As such, Table 1 portrays that the AVE values for all constructs are indeed higher than 0.8 , which indicates acceptable convergent validity. Finally, in order to test for multicollinearity issue, this study tested the variance inflation factors (VIF). The VIF values for all variables are below 1.5, thus indicating the absence of multicollinearity issues [57].

As for the discriminant validity based on the Fornell-Larcker criterion, the AVE for each indicator should be greater than the highest squared correlation between the constructs. As noted in Table 2, all constructs did meet this criterion. Meanwhile, the Heterotrait-Monotrait Ratio (HTMT) denotes an estimate of the correlation between constructs, paralleling the disattenuated construct score. With the value of 0.9 as the threshold, this study concluded that there is no evidence signifying lack of discriminant validity. Lastly, the loading and cross-loading values presented in Table 3 and Figure 1 
show that all the indicator loadings exceed 0.7 . The cross-loadings in Table 3 exemplify that all loadings for the indicators are higher than the total cross-loadings, hence re-affirming discriminant validity.

Table 1. Reliability and validity.

\begin{tabular}{ccccccccc}
\hline Variables & No. Items & Mean & SD & CA & DG rho & CR & AVE & VIF \\
\hline EL & 4 & 3.263 & 1.045 & 0.974 & 0.980 & 0.981 & 0.926 & 1.087 \\
EC & 4 & 4.303 & 0.794 & 0.978 & 0.978 & 0.984 & 0.938 & 1.087 \\
ATE & 4 & 3.932 & 0.717 & 0.920 & 0.924 & 0.944 & 0.808 & 1.271 \\
NRB & 4 & 3.312 & 1.000 & 0.971 & 0.972 & 0.978 & 0.919 & 1.171 \\
PBC & 4 & 3.362 & 0.810 & 0.957 & 0.958 & 0.969 & 0.887 & 1.330 \\
WPEFP & 6 & 3.174 & 0.997 & 0.980 & 0.982 & 0.984 & 0.911 & 1.369 \\
PBEFP & 6 & 3.625 & 1.332 & 0.983 & 0.984 & 0.986 & 0.922 & - \\
\hline
\end{tabular}

Note: EL: Eco-Literacy; EC: Environmental Concern; ATE: Attitudes Towards Environmentally Friendly Products; NRB: Normative Beliefs; PBC: Perceived Behavioral Control; WPEFP: Willingness to Pay for Environmentally Friendly Products; PBEFP: Payment Behavior for Environmentally Friendly Products; SD: Standard Deviation; CA: Cronbach's Alpha; DG rho-Dillon-Goldstein's rho; CR-Composite Reliability; AVE-Average Variance Extracted; VIF-Variance Inflation Factors. Source: author's data analysis.

Table 2. Discriminant validity.

\begin{tabular}{|c|c|c|c|c|c|c|c|c|c|c|c|c|c|}
\hline \multicolumn{8}{|c|}{ Fornell-Larcker Criterion } & \multicolumn{6}{|c|}{ Heterotrait-Monotrait Ratio (HTMT) } \\
\hline & EL & EC & ATE & NRB & PBC & WPEFP & PBEFP & EL & EC & ATE & NRB & PBC & WPEFP \\
\hline EL & 0.962 & & & & & & & - & & & & & \\
\hline EC & 0.283 & 0.968 & & & & & & 0.292 & - & & & & \\
\hline ATE & 0.268 & 0.453 & 0.899 & & & & & 0.280 & 0.476 & - & & & \\
\hline NRB & 0.671 & 0.248 & 0.288 & 0.959 & & & & 0.691 & 0.254 & 0.304 & - & & \\
\hline $\mathrm{PBC}$ & 0.403 & 0.282 & 0.439 & 0.352 & 0.942 & & & 0.415 & 0.291 & 0.469 & 0.365 & - & \\
\hline WPEFP & 0.501 & 0.308 & 0.366 & 0.365 & 0.519 & 0.955 & & 0.512 & 0.314 & 0.383 & 0.372 & 0.535 & - \\
\hline PBEFP & 0.377 & 0.363 & 0.395 & 0.311 & 0.566 & 0.503 & 0.960 & 0.384 & 0.370 & 0.416 & 0.318 & 0.583 & 0.511 \\
\hline
\end{tabular}

Note: EL: Eco-Literacy; EC: Environmental Concern; ATE: Attitudes Towards Environmentally Friendly Products; NRB: Normative Beliefs; PBC: Perceived Behavioral Control; WPEFP: Willingness to Pay for Environmentally Friendly Products; PBEFP: Payment Behavior for Environmentally Friendly Products. Source: author's data analysis.

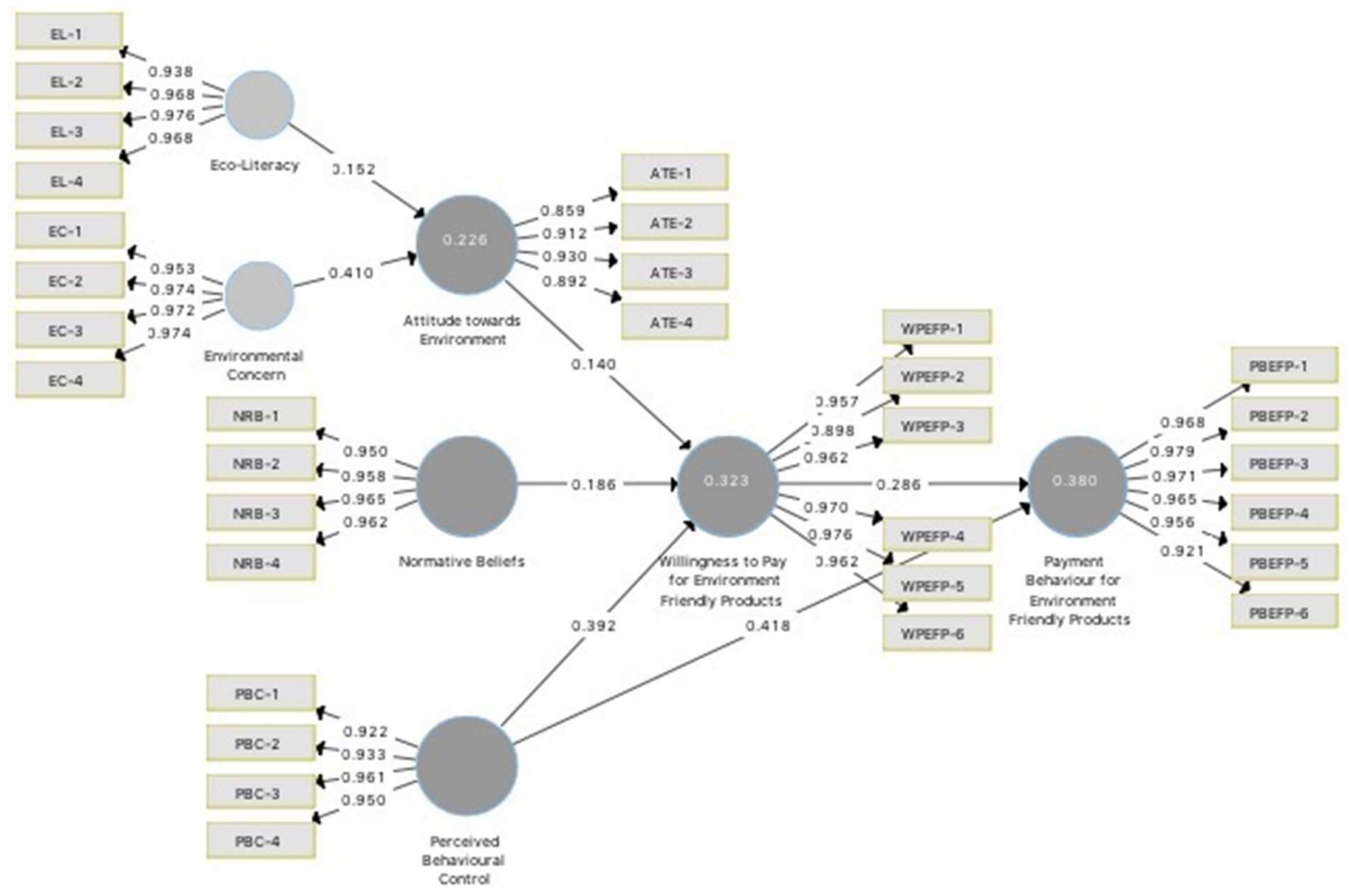

Figure 1. Research model and analysis. 
Table 3. Loadings and cross-loading.

\begin{tabular}{|c|c|c|c|c|c|c|c|}
\hline & EL & SE & ATE & SUN & PBC & IEFP & CEFP \\
\hline \multicolumn{8}{|l|}{ Eco-Literacy (EL) } \\
\hline You would prefer to check the eco-labels and certifications on green products before purchase & 0.938 & 0.297 & 0.221 & 0.641 & 0.341 & 0.480 & 0.320 \\
\hline You would prefer to gain substantial information on green products before purchase & 0.968 & 0.281 & 0.258 & 0.647 & 0.380 & 0.482 & 0.363 \\
\hline Your knowledge helps to buy products and packages that are environmentally safe & 0.976 & 0.263 & 0.278 & 0.656 & 0.412 & 0.487 & 0.385 \\
\hline You know the products and packages that reduce the amount of waste that end up in landfills & 0.968 & 0.256 & 0.268 & 0.642 & 0.411 & 0.481 & 0.377 \\
\hline \multicolumn{8}{|l|}{ Environmental Concern (EC) } \\
\hline You believe major social changes are necessary to protect the natural environment & 0.267 & 0.953 & 0.434 & 0.246 & 0.269 & 0.292 & 0.348 \\
\hline You believe humans must live in harmony with nature in order to survive & 0.290 & 0.974 & 0.449 & 0.258 & 0.266 & 0.294 & 0.355 \\
\hline You think environmental problems are very important to address & 0.254 & 0.972 & 0.430 & 0.224 & 0.270 & 0.297 & 0.327 \\
\hline You think we should care more about environmental problems & 0.286 & 0.974 & 0.441 & 0.234 & 0.287 & 0.310 & 0.375 \\
\hline \multicolumn{8}{|l|}{ Attitudes Towards Environmentally Friendly Products (ATE) } \\
\hline Environmental protection is important to you when making purchase decision & 0.207 & 0.388 & 0.859 & 0.244 & 0.406 & 0.300 & 0.381 \\
\hline Between EF and conventional products, you prefer environmentally friendly one & 0.219 & 0.386 & 0.912 & 0.246 & 0.438 & 0.322 & 0.368 \\
\hline Using environmentally friendly products is necessary to mitigate global warming & 0.272 & 0.434 & 0.930 & 0.283 & 0.381 & 0.341 & 0.344 \\
\hline You think that purchasing environmentally friendly products is favorable & 0.259 & 0.417 & 0.892 & 0.261 & 0.359 & 0.348 & 0.331 \\
\hline \multicolumn{8}{|l|}{ Normative Beliefs (NRB) } \\
\hline Your family think you should practice environmentally friendly behavior & 0.654 & 0.214 & 0.257 & 0.950 & 0.320 & 0.330 & 0.270 \\
\hline Your friends think you should practice environmentally friendly behavior & 0.647 & 0.211 & 0.273 & 0.958 & 0.349 & 0.348 & 0.306 \\
\hline Your family think you should purchase environmentally friendly products & 0.637 & 0.265 & 0.283 & 0.965 & 0.346 & 0.358 & 0.312 \\
\hline Your friends think you should purchase environmentally friendly products & 0.637 & 0.259 & 0.292 & 0.962 & 0.336 & 0.360 & 0.302 \\
\hline \multicolumn{8}{|l|}{ Perceived Behavioral Control (PBC) } \\
\hline You see yourself as capable of purchasing environmentally friendly products in future & 0.421 & 0.322 & 0.422 & 0.348 & 0.922 & 0.495 & 0.528 \\
\hline You have resources to purchase environmentally friendly products & 0.352 & 0.226 & 0.401 & 0.328 & 0.933 & 0.474 & 0.508 \\
\hline You have willingness to purchase environmentally friendly products & 0.380 & 0.277 & 0.433 & 0.337 & 0.961 & 0.505 & 0.554 \\
\hline There are likely to be plenty of opportunities for you to purchase EFPs & 0.365 & 0.234 & 0.395 & 0.313 & 0.950 & 0.481 & 0.541 \\
\hline \multicolumn{8}{|l|}{ Willingness to Pay for Environmentally Friendly Products (WPEFP) } \\
\hline You would pay extra for EFPs even if the performance were same as the conventional products & 0.492 & 0.300 & 0.363 & 0.359 & 0.511 & 0.957 & 0.503 \\
\hline You would pay extra for EFPs even if it had a less-appealing design & 0.397 & 0.275 & 0.296 & 0.277 & 0.472 & 0.898 & 0.447 \\
\hline The probability that you will pay extra to buy EFPs is very high & 0.466 & 0.290 & 0.338 & 0.336 & 0.476 & 0.962 & 0.444 \\
\hline When you replace any household appliance, you are willing to pay extra to purchase EF one & 0.486 & 0.294 & 0.355 & 0.348 & 0.487 & 0.970 & 0.480 \\
\hline Compared with ordinary non-green products, you are more willing to pay extra to buy EFPs & 0.516 & 0.307 & 0.375 & 0.380 & 0.526 & 0.976 & 0.506 \\
\hline You intend to pay more for environmentally friendly products & 0.504 & 0.297 & 0.359 & 0.380 & 0.498 & 0.962 & 0.493 \\
\hline \multicolumn{8}{|l|}{ Payment Behavior for Environmentally Friendly Products (PBEFP) } \\
\hline You pay extra for products manufactured or grown in an environmentally friendly manner & 0.348 & 0.348 & 0.393 & 0.295 & 0.559 & 0.499 & 0.968 \\
\hline You pay extra for eco-labeled products, i.e., non-polluting products & 0.355 & 0.357 & 0.382 & 0.299 & 0.560 & 0.486 & 0.979 \\
\hline You pay extra for products packed in reusable containers (glass jars, etc.) & 0.371 & 0.343 & 0.393 & 0.302 & 0.560 & 0.475 & 0.971 \\
\hline You pay extra for low-energy appliances & 0.355 & 0.338 & 0.373 & 0.278 & 0.562 & 0.465 & 0.965 \\
\hline You talk to people about the reasons/benefits why you pay more for EFPs & 0.357 & 0.353 & 0.367 & 0.285 & 0.517 & 0.502 & 0.956 \\
\hline You set a positive environmental example (paying extra for EFPs) for your friends to follow & 0.391 & 0.352 & 0.364 & 0.333 & 0.500 & 0.470 & 0.921 \\
\hline
\end{tabular}

Note: (1) EF: Environmentally Friendly; EFP: Environmentally Friendly Products; (2) the Bold-Italic values in the matrix above are the item loadings and others are cross-loadings. Source: author's data analysis. 


\subsection{Path Analysis}

The path coefficients, as noted in Figure 1 and Table 4, display that the coefficient value for eco-literacy on attitudes towards environmental-friendly products among low-income household heads in coastal Peninsular Malaysia (Hypothesis 2 is 0.152 with a $p$-value of 0.000 (below $5 \%$ level of significance). The findings indicate that the level of eco-literacy among the respondents has a positive effect on their attitudes towards environmentally friendly products. However, the $f^{2}$ value of 0.027 hints at a relatively small effect of eco-literacy on attitudes towards environmentally friendly products. Meanwhile, the coefficient value for environmental concern on attitudes towards environmentally friendly products (Hypothesis 3) is 0.410 with a $p$-value of 0.000 (below $5 \%$ level of significance).

The findings show that the level of environmental concern among low-income household heads has a positive effect on their attitudes towards environmentally friendly products. Furthermore, the standardized regression coefficients show that the aspect of environmental concern does have a relatively higher effect on attitudes towards environmentally friendly products, as compared to that of eco-literacy. In addition, the $f^{2}$ value of 0.200 indicates a moderate effect of environmental concern on attitudes towards environmentally friendly products among the respondents, which is also relatively higher than that for eco-literacy. The $r^{2}$ value, which represents the degree of explained variance, appears to be 0.226 , hence signifying an essential proportion $(22.6 \%)$ of the variation in the respondents' attitudes towards environmentally friendly products that can be explained by their levels of eco-literacy and environmental concern. Finally, the $Q^{2}$ value of 0.170 shows that the level of eco-literacy and environmental concern displayed among the respondents has medium predictive relevance for their attitudes towards environmentally friendly products.

The path coefficients, as tabulated in Table 4, show that the coefficient value for attitudes towards environmentally friendly products on willingness to pay for environmental-friendly products among the low-income household heads in coastal Peninsular Malaysia (Hypothesis 1) is 0.140 with a $p$-value of 0.008 (below $5 \%$ level of significance). The outcomes signify that the attitudes displayed by the low-income household heads towards environmentally friendly products have a significantly positive effect on their willingness to pay for environmental-friendly products. The $f^{2}$ value of 0.023 shows the small effect of attitudes towards environmentally friendly products on willingness to pay for environmentally friendly products among the respondents. The coefficient value for normative beliefs on willingness to pay for environmentally friendly products among the respondents (Hypothesis 6) is 0.186 with a $p$-value of 0.000 (below $5 \%$ level of significance). The findings showcase that normative beliefs have a significant effect on willingness to pay for environmentally friendly products. Moreover, the $f^{2}$ value of 0.044 indicates a low effect of normative beliefs on willingness to pay for environmentally friendly products among the low-income household heads in coastal Peninsular Malaysia. Meanwhile, the coefficient value for perceived behavioral control on willingness to pay for environmentally friendly products (Hypothesis 7) is 0.392 with a $p$-value of 0.000 (below $5 \%$ level of significance). The results show that the level of perceived behavioral control among the respondents has a significantly positive effect on their willingness to pay for environmentally friendly products. The standardized regression coefficients further display that perceived behavioral control has a relatively higher effect on willingness to pay for environmentally friendly products, followed by normative beliefs and attitudes towards environmentally friendly products. Moreover, the $f^{2}$ value of 0.171 signifies a moderate effect of perceived behavioral control on willingness to pay for environmentally friendly products among the respondents, which is also relatively higher than that for normative beliefs and attitudes. The $r^{2}$ value, which represents the degree of explained variance, is 0.323 , hence indicating that a significant proportion $(32.3 \%)$ of the variation in respondents' willingness to pay for environmentally friendly products can be explained by their attitudes towards environmentally friendly products, normative beliefs, and perceived behavioral control. Finally, the $Q^{2}$ value of 0.273 indicates that the respondents' attitudes towards environmentally friendly products, normative beliefs, and perceived behavioral control have medium predictive relevance for the respondents' willingness to pay for environmentally friendly products. 
Table 4. Path Coefficients.

\begin{tabular}{|c|c|c|c|c|c|c|c|c|c|c|}
\hline Hypo & & Beta & CI-Min & CI-Max & $t$ & $p$ & $r^{2}$ & $f^{2}$ & $Q^{2}$ & Decision \\
\hline \multicolumn{11}{|c|}{ Factors Effecting Attitudes } \\
\hline $\mathrm{H} 2$ & $\mathrm{EL} \rightarrow \mathrm{ATE}$ & 0.152 & 0.076 & 0.223 & 3.549 & $<0.01$ & \multirow{2}{*}{0.226} & 0.027 & \multirow[b]{2}{*}{0.170} & Accept \\
\hline H3 & $\mathrm{EC} \rightarrow \mathrm{ATE}$ & 0.410 & 0.324 & 0.497 & 7.805 & $<0.01$ & & 0.200 & & Accept \\
\hline \multicolumn{11}{|c|}{ Factors Effecting Willingness to Pay for Environmentally Friendly Products } \\
\hline H1 & $\mathrm{ATE} \rightarrow \mathrm{WPEFP}$ & 0.140 & 0.039 & 0.230 & 2.422 & $<0.01$ & \multirow{3}{*}{0.323} & 0.023 & \multirow{3}{*}{0.273} & Accept \\
\hline H6 & $\mathrm{NRB} \rightarrow \mathrm{WPEFP}$ & 0.186 & 0.116 & 0.271 & 3.791 & $<0.01$ & & 0.044 & & Accept \\
\hline $\mathrm{H7}$ & $\mathrm{PBC} \rightarrow \mathrm{WPEFP}$ & 0.392 & 0.312 & 0.473 & 7.956 & $<0.01$ & & 0.171 & & Accept \\
\hline \multicolumn{11}{|c|}{ Factors Effecting Payment Behaviour for Environmentally Friendly Products } \\
\hline H8 & $\mathrm{PBC} \rightarrow \mathrm{PBEFP}$ & 0.418 & 0.338 & 0.500 & 8.472 & $<0.01$ & \multirow[b]{2}{*}{0.380} & 0.206 & \multirow[b]{2}{*}{0.326} & Accept \\
\hline H9 & $\mathrm{WPEFP} \rightarrow \mathrm{PBEFP}$ & 0.286 & 0.198 & 0.372 & 5.437 & $<0.01$ & & 0.096 & & Accept \\
\hline \multicolumn{2}{|c|}{ Mediating Effect of Attitudes } & Beta & $\mathrm{CI}-\mathrm{Min}$ & CI-Max & $\mathrm{t}$ & $p$ & \multicolumn{4}{|c|}{ Decision } \\
\hline $\mathrm{H} 4$ & $\mathrm{EL} \rightarrow \mathrm{ATE} \rightarrow \mathrm{WPEFP}$ & 0.021 & 0.005 & 0.042 & 1.925 & $<0.05$ & \multirow{2}{*}{\multicolumn{4}{|c|}{$\begin{array}{l}\text { Mediation } \\
\text { Mediation }\end{array}$}} \\
\hline H5 & $\mathrm{EC} \rightarrow \mathrm{ATE} \rightarrow \mathrm{WPEFP}$ & 0.057 & 0.018 & 0.099 & 2.388 & $<0.01$ & & & & \\
\hline \multicolumn{11}{|c|}{ Mediating Effect of Willingness to Pay for Environmentally Friendly Products } \\
\hline $\mathrm{H} 10$ & $\mathrm{ATE} \rightarrow \mathrm{WPEFP} \rightarrow \mathrm{PBEFP}$ & 0.040 & 0.010 & 0.075 & 2.004 & $<0.05$ & \multicolumn{4}{|c|}{ Mediation } \\
\hline H11 & $\mathrm{SUN} \rightarrow \mathrm{WPEFP} \rightarrow \mathrm{PBEFP}$ & 0.053 & 0.026 & 0.085 & 2.973 & $<0.01$ & \multicolumn{4}{|c|}{ Mediation } \\
\hline H12 & $\mathrm{PBC} \rightarrow \mathrm{WPEFP} \rightarrow \mathrm{PBEFP}$ & 0.112 & 0.075 & 0.150 & 5.040 & $<0.01$ & \multicolumn{4}{|c|}{ Mediation } \\
\hline
\end{tabular}

Note: EL: Eco-Literacy; EC: Environmental Concern; ATE: Attitudes Towards Environmentally Friendly Products; NRB: Normative Beliefs; PBC: Perceived Behavioral Control; WPEFP: Willingness to Pay for Environmentally Friendly Products; PBEFP: Payment Behavior for Environmentally Friendly Products. Source: author's data analysis.

Finally, the path coefficients, as noted in Table 4, display that the coefficient value for perceived behavioral control on payment behavior for environmentally friendly products among the low-income household heads in coastal Peninsular Malaysia (Hypothesis 8) is 0.418 with a $p$-value of 0.000 (below $5 \%$ level of significance). The findings exhibit that the level of perceived behavioral control among the respondents has a significantly positive effect on their payment behavior for environmentally friendly products. The $f^{2}$ value of 0.206 points out a moderate effect of perceived behavioral control on payment behavior for environmentally friendly products among the respondents. The coefficient value for willingness to pay for environmental-friendly products on payment behavior for green products (Hypothesis 9) is 0.286 with a $p$-value of 0.000 (below $5 \%$ level of significance). The outcomes show that willingness among the respondents to pay for environmentally friendly products has a significantly positive effect on their payment behavior for green products. The standardized regression coefficients signify that perceived behavioral control has a relatively higher effect on payment behavior for environmentally friendly products than that of willingness to pay for green products. Moreover, the $f^{2}$ value of 0.096 indicates a weak effect of willingness to pay for environmentally friendly products on payment behavior for green products among the respondents, which is also relatively lower than that for perceived behavioral control. Meanwhile, the $r^{2}$ value, which is 0.380 , points out that a significant proportion $(38.0 \%)$ of the variation in respondents' payment behavior for environmentally friendly products can be explained by their level of willingness to pay for environmentally friendly products and perceived behavioral control. Finally, the $Q^{2}$ value of 0.326 shows that the level of willingness to pay among the respondents for environmentally friendly products and perceived behavioral control have medium-to-high predictive relevance for their payment behavior for environmentally friendly products.

\subsection{Mediating Effects}

As for the mediating effects of attitudes towards environmentally friendly products, normative beliefs, perceived behavioral control, and willingness to pay for environmentally friendly products, the study presents indirect effect coefficients, confidence intervals, and $p$-values in Table 4 . The results show that eco-literacy (Hypothesis 4 ) has a significantly ( $p$-values $<0.05$ ) indirect effect on willingness to pay for environmentally friendly products among low-income household heads in Coastal Peninsular Malaysia; which ratifies that attitudes towards environmentally friendly products mediate the 
relationship between eco-literacy and willingness to pay for environmentally friendly products. As for environmental concern (Hypothesis 5 ), it displays a significantly positive ( $p$-values $<0.05$ ) and indirect effect on willingness to pay for environmentally friendly products among the respondents, which confirms that attitudes towards environmentally friendly products mediate the correlation between environmental concern and willingness to pay for green products.

The findings further revealed that attitudes towards environmental-friendly products (Hypothesis 10) have a significantly positive ( $p$-values $<0.05$ ) and indirect effect on payment behavior for environmentally friendly products among low-income household heads in Coastal Peninsular Malaysia, which affirms that willingness to pay for environmentally friendly products mediates the relationship between attitudes towards environmentally friendly products and payment behavior for green products. The outcomes also show that normative beliefs (Hypothesis 11) have a significantly ( $p$-values $<0.05$ ) indirect effect on payment behavior for environmentally friendly products among the respondents, thus sanctioning that willingness to pay for green products mediates the correlation between normative beliefs and payment behavior for green products. Finally, the results for perceived behavioral control (Hypothesis 12) reveal a significantly positive $(p$-values $<0.05)$ and indirect effect on payment behavior for green products among low-income household heads in Coastal Peninsular Malaysia, which ratifies that willingness to pay for environmentally friendly products mediates the relationship between perceived behavioral control and payment behavior for green products.

\subsection{Importance of Performance Matrix Analysis}

Next, a post-hoc importance-performance matrix analysis (IPMA) was performed using payment behavior for environmentally friendly products as the target construct. The total effect values (importance score) and the performance values (ranging from 0 for 'lowest performance' to 100 for 'highest performance') are tabulated in Table 5. The outcomes reveal that perceived behavioral control and willingness to pay for environmentally friendly products are the most important factors that influence the payment behavior for green products.

Table 5. Performance and total effects.

\begin{tabular}{|c|c|c|c|c|c|}
\hline \multirow{2}{*}{$\begin{array}{c}\begin{array}{c}\text { Target } \\
\text { Construct }\end{array} \\
\text { Variables }\end{array}$} & \multicolumn{2}{|c|}{$\begin{array}{c}\text { Payment Behavior for } \\
\text { Environmentally Friendly Products }\end{array}$} & & \multicolumn{2}{|c|}{$\begin{array}{c}\text { Payment Behavior for } \\
\text { Environmentally Friendly Products }\end{array}$} \\
\hline & Total Effect & Performance & & Total Effect & Performance \\
\hline EL & 0.01 & 56.82 & NRB & 0.07 & 57.78 \\
\hline $\mathrm{EC}$ & 0.03 & 82.61 & PBC & 0.87 & 59.08 \\
\hline ATE & 0.07 & 73.45 & WPEFP & 0.38 & 54.44 \\
\hline
\end{tabular}

Note: EL: Eco-Literacy; EC: Environmental Concern; ATE: Attitudes Towards Environmentally Friendly Products; NRB: Normative Beliefs; PBC: Perceived Behavioral Control; WPEFP: Willingness to Pay for Environmentally Friendly Products. Source: author's data analysis.

\section{Discussion and Implications}

Consumers of today have been enlightened about their critical role in protecting the environment [16]. Hence, in an attempt to comprehend the predictors of environmentally responsible consumption from the emerging stance of economies, this study has determined the factors that influence willingness to pay and payment behavior for environmentally friendly products through the use of an extended TPB framework. The findings of this study reveal that the level of eco-literacy and environmental concern among the respondents has a significantly positive effect on their attitudes towards environmentally friendly products. This finding is in line with several existing studies $[1,28,32,35,36]$ supporting that environmental knowledge and awareness do promote positively strong attitudes towards intention to pay and payment behavior for environmentally friendly products. The findings further display that attitudes among the respondents towards environmentally friendly products have a significantly positive effect on their willingness to pay for green products. This finding thus conforms to the TPB [15] and the existing literature [1,2,12,30], which signifies that the degree of 
individuals' perceptions of the performance of green purchase behavior determines their willingness to pay for environmentally friendly products.

Meanwhile, normative beliefs held by the low-income household heads were also found to have a significantly positive effect on their willingness to pay for green products. This finding supports the theories of and is in line with Wang et al. [29] and Adnan et al. [14], who advocated that in a collectivist society, such as that in Malaysia (being an Asian country), social norms have more contributory effects at influencing behavioral intentions towards purchase of green products than their personal counterparts. This finding further extends the notion presented by Wu and Chen [16], which suggests that in a collectivist society, normative beliefs do not only effect behavioral intention indirectly (through subjective norms), but also directly. As for behavioral control, the outcomes reveal that the level of perceived behavioral control exerted a positively significant influence on willingness among respondents to pay for green products. This finding further draws support from the TPB [15], which is also in line with the relevant existing literature [1,3,29].

The results further portray a significantly positive effect of the level of perceived behavioral control and willingness to pay for green products among the respondents on payment behavior. This finding empirically supports TPB, thus re-establishing both perceived behavioral control and intention (willingness to pay) as significant predictors of behavior (payment behavior), in particular within the context of environmentally friendly products among selected low-income households of Coastal Peninsular Malaysia in the sphere of the emerging economy [15,16,42]. Interestingly, in regard to this finding, the higher effect value of perceived behavioral control indicates that payment behavior for green products is a non-volitional behavior, which poses difficulties in execution and therefore depends more on perceived availability of recourses and individual abilities instead of their willingness to pay $[28,43]$.

On the other hand, in terms of mediation effects, attitudes towards environmentally friendly products appeared to significantly mediate the correlation of eco-literacy and environmental concern with willingness to pay for environmentally friendly products. This finding supports the extended TPB model employed in this study and falls in line with prior related studies $[1,28,35,37]$. Finally, as hypothesized, willingness to pay for environmentally friendly products was found to significantly mediate the relationships of attitudes towards environmentally friendly products, normative beliefs, and perceived behavioral control with payment behavior for green products. Furthermore, this finding reflects the significantly indirect effect of attitude among the respondents towards environmentally friendly products, normative beliefs, and perceived behavioral control on their payment behavior for environmentally friendly products, which is in agreement with Ajzen [15]. Last but not least, the results for performance and total effects signify that perceived behavioral control and willingness to pay for environmentally friendly products are the factors that contribute most towards the payment behavior for environmentally friendly products among selected low-income household heads in Coastal Peninsular Malaysia [15,16,42,43].

\section{Conclusions}

In line with Kai and Haokai [28], this study argues that developing and championing environmentally friendly products and services demands effective public behavior in favor of the socio-economic environment. As such, this study investigated the influence of consumers' psychological factors (i.e., attitudes, normative beliefs, and perceived behavioral controls) on willingness to pay and payment behavior for environmentally friendly products among selected low-income households in Coastal Peninsular Malaysia. The overall outcomes from various statistical tests have confirmed that the extended TPB model employed by this study is indeed appropriate for the studied group. Moreover, the literature review has revealed interesting but scant insights into consumers' willingness to pay for green products, particularly in light of the emerging economies. Theoretically, this study seems to make a substantial contribution towards the growing body of relevant literature pertaining to intention behavior by empirically validating a comprehensive model 
for environmentally friendly products within the context of low-income households in Malaysia. In fact, this study does not only contribute towards the TPB by simply providing empirical evidence that reaffirms its applicability, but it also significantly contributes towards the TPB by broadening the explanatory power of the TPB through integration of subcomponents (eco-literacy and environmental concern) with certain constructs (attitudes) of the theory. Hence, this study extends the TPB and widens its scope by examining willingness to pay and payment behavior towards environmentally friendly products through the lenses of low-income households.

In terms of practical implication, this study draws the attention of policy makers and green organizations towards the focus areas so as to enhance public sensitivity towards environmental issues and further drive consumer preferences towards ecologically-conscious purchasing behavior, thus resulting in increased demand and adoption of green products that support the growth of green businesses. Furthermore, governments and developmental organizations should adopt policies and programs in order to enhance environmental knowledge and awareness among low-income households to promote the purchase of green products. Moreover, relevant authorities should work to encourage positive social norms, mainly to induce green consumerism. In addition, adequate resources and facilities, for example, subsidiaries, availability of green products, etc., have to be ascertained so as to improve the perceived behavioral control, which in turn, generates willingness to pay and payment behavior of environmentally friendly products, particularly among those with low income.

As for green firms, the findings of this study could be applied to identify the source of green product purchase intentions among consumers, which can immensely aid in devising viable strategies and acquiring market share for environmentally friendly products. On top of that, relevant firms may use the outcomes of this study to formulate policies and strategies to develop products, to understand customer needs, and, ultimately, to retain consumers. In particular, from the stance of the local perspective, the results of this study could serve as a guideline for organizations that plan to penetrate into the Malaysian market in strategizing their marketing approaches that would further encourage consumers to pay for green products.

Nevertheless, all studies, including this one, have limitations. It is noteworthy to highlight that this study could not accommodate all factors that may affect consumers' willingness to pay and payment behavior into this model. Furthermore, this study only focused on a specific income group from a single country, thus limiting the generalizability of its findings. In terms of methodological limitation, this study depended solely on the cross-sectional quantitative approach. Perhaps, a multiple method approach that determines the aspects of robustness and causality based on qualitative methods or longitudinal data could further prove the reliability of the findings retrieved from this present study.

Finally, this study perceives environmentally friendly products as generally representing all green products. In reality, purchase intention and adoption of specific categories of green products and services, such as green vehicles, organic food, environmental-friendly hotels, etc., could take a different direction. Hence, it is recommended that future researchers should focus on specific environmentally friendly products and services, drawing their samples from varied economic and social groups living across the globe, which could reveal new and interesting research angles that lead to a better understanding of environmentally friendly consumption, which appears to be essential for sustainable development.

Author Contributions: Lead author Abdullah Al Mamun, who was also the lead researcher of the research grant that was received, prepared the research proposal, managed the research project, designed the questionnaire, analyzed the data, and wrote this paper. Syed Ali Fazal, Ghazali Bin Ahmad, Mohd Rafi Bin Yaacob and Mohd. Rosli Mohamad contributed to the development of the research model, the literature review, the sample selection, the data collection, and the preparation of the manuscript.

Acknowledgments: This study was funded by the RMIC, Universiti Malaysia Kelantan, Malaysia under the grant titled 'Short Term Research Grant (SGJP-USM) (Grant Code: R/MyRA/A01.00/00826A/002/2017/000404)'. Project title: Intention and Behavior towards Eco-Friendly means to Eradicate Poverty: A Study among Low Income Households in Coastal Peninsular Malaysia. Total Grant: RM31224.93 (Ringgit Malaysia).

Conflicts of Interest: The authors declare no conflict of interest. 


\section{References}

1. Maichum, K.; Parichatnon, S.; Peng, K. Application of the Extended Theory of Planned Behavior Model to Investigate Purchase Intention of Green Products among Thai Consumers. Sustainability 2016, 8, 1077. [CrossRef]

2. Mei, O.J.; Ling, K.C.; Piew, T.H. The antecedents of green purchase intention among Malaysian consumers. Asian Soc. Sci. 2012, 8, 248-263. [CrossRef]

3. Afroz, R.; Masud, M.; Akhtar, R.; Islam, M.; Duasa, J. Consumer purchase intention towards environmentally friendly vehicles: An empirical investigation in Kuala Lumpur. Environ. Sci. Pollut. R. 2015, 22, 16153-16163. [CrossRef] [PubMed]

4. Osman, A.; Isa, F.; Othman, S.; Jaganathan, M. Attitude towards recycling among business undergraduate students in Malaysia. Am. Eurasian J. Sustain. Agric. 2014, 8, 6-12.

5. Essoussi, L.H.; Linton, J.D. New or recycled products: How much are consumers willing to pay? J. Consum. Mark. 2010, 27, 458-468. [CrossRef]

6. Chen, K.; Deng, T. Research on the green purchase intentions from the perspective of product knowledge. Sustainability 2016, 8, 943. [CrossRef]

7. Mishra, P.; Sharma, P. Green marketing in India: Emerging opportunities and challenges. J. Eng. Sci. Manag. Educ. 2010, 3, 9-14.

8. Chen, T.B.; Chai, L.T. Attitude towards the environment and green products: consumers' perspective. Manag. Sci. Eng. 2010, 4, 27-39.

9. Qader, I.; Zainuddin, Y. The influence of media exposure, safety and health concerns, and self-efficacy on environmental attitudes towards electronic green products. Asian Acad. Manag. J. 2011, 16, 167-186.

10. Lanzini, P.; Testa, F.; Iraldo, F. Factors affecting drivers' willingness to pay for biofuels: The case of Italy. J. Clean. Prod. 2016, 112, 2684-2692. [CrossRef]

11. Ha, H.; Janda, S. Predicting consumer intentions to purchase energy-efficient products. J. Consum. Mark. 2012, 29, 461-469. [CrossRef]

12. Al-Mamun, A.; Nawi, N.B.C.; Zainol, N.R.B. Entrepreneurial competencies and performance of informal micro-enterprises in Malaysia. Mediterr. J. Soc. Sci. 2016, 7, 273-281. [CrossRef]

13. Brécard, D.; Hlaimi, B.; Lucas, S.; Perraudeau, Y.; Salladarré, F. Determinants of demand for green products: An application to eco-label demand for fish in Europe. Ecol. Econ. 2009, 69, 115-125. [CrossRef]

14. Adnan, N.; Nordin, S.M.; Rahman, I.; Rasli, A.M. A new era of sustainable transport: An experimental examination on forecasting adoption behavior of EVs among Malaysian consumer. Transport. Res. A-Pol. 2017, 103, 279-295. [CrossRef]

15. Ajzen, I. The theory of planned behavior. Organ. Behav. Hum. Dec. 1991, 50, 179-211. [CrossRef]

16. Wu, S.; Chen, J. A model of green consumption behavior constructed by the theory of planned behavior. Int. J. Mark. Stud. 2014, 6, 119-132. [CrossRef]

17. Chen, M.F.; Tung, P.J. Developing an extended theory of planned behavior model to predict consumers' intention to visit green hotels. Int. J. Hosp. Manag. 2014, 36, 221-230. [CrossRef]

18. Han, H.; Hsu, L.T.J.; Sheu, C. Application of the theory of planned behavior to green hotel choice: Testing the effect of environmental friendly activities. Tour. Manag. 2010, 31, 325-334. [CrossRef]

19. Han, H.; Hsu, L.T.J.; Lee, J.S.; Sheu, C. Are lodging customers ready to go green? An examination of attitudes, demographics, and eco-friendly intentions. Int. J. Hosp. Manag. 2011, 30, 345-355. [CrossRef]

20. Kim, H.Y.; Chung, J.E. Consumer purchase intention for organic personal care products. J. Consum. Mark. 2011, 28, 40-47.

21. Hultman, M.; Kazeminia, A.; Ghasemi, V. Intention to visit and willingness to pay premium for ecotourism: The impact of attitude, materialism, and motivation. J. Bus. Res. 2015, 68, 1854-1861. [CrossRef]

22. Kim, Y.; Han, H. Intention to pay conventional-hotel prices at a green hotel-A modification of the theory of planned behavior. J. Sustain. Tour. 2010, 18, 997-1014. [CrossRef]

23. Chen, M.F. Consumer attitudes and purchase intentions in relation to organic foods in Taiwan: Moderating effects of food-related personality traits. Food Qual. Preference 2007, 18, 1008-1021. [CrossRef]

24. Tarkiainen, A.; Sundqvist, S. Subjective norms, attitudes and intentions of Finnish consumers in buying organic food. Br. Food J. 2005, 107, 808-822. [CrossRef] 
25. Voon, J.P.; Ngui, K.S.; Agrawal, A. Determinants of willingness to purchase organic food: An exploratory study using structural equation modeling. Int. Food Agribus. Manag. Assoc. 2011, 14, 103-120.

26. Hansla, A.; Gamble, A.; Juliusson, A.; Gärling, T. Psychological determinants of attitude towards and willingness to pay for green electricity. Energy Policy 2008, 36, 768-774. [CrossRef]

27. Kim, Y.J.; Njite, D.; Hancer, M. Anticipated emotion in consumers' intentions to select eco-friendly restaurants: Augmenting the theory of planned behavior. Int. J. Hosp. Manag. 2013, 34, 255-262. [CrossRef]

28. Kai, C.; Haokai, L. Factors affecting consumers' green commuting. Eurasia J. Math. Sci. Technol. Educ. 2016, 12, 527-538.

29. Wang, S.; Fan, J.; Zhao, D.; Yang, S.; Fu, Y. Predicting consumers' intention to adopt hybrid electric vehicles: Using an extended version of the theory of planned behavior model. Transportation 2016, 43, 123-143. [CrossRef]

30. Tsen, C.H.; Phang, G.; Hasan, H.; Buncha, M.R. Going green: A study of consumers' willingness to pay for green products in Kota Kinabalu. Int. J. Bus. Soc. 2006, 7, 40-52.

31. Laroche, M.; Bergeron, J.; Barbaro-Forleo, G. Targeting consumers who are willing to pay more for environmentally friendly products. J. Consum. Mark. 2001, 18, 503-520. [CrossRef]

32. Cheah, I.; Phau, I. Attitudes towards environmentally friendly products: The influence of ecoliteracy, interpersonal influence and value orientation. Mark. Intell. Plan. 2011, 29, 452-472. [CrossRef]

33. Aminrad, Z.; Zakariya, S.Z.B.S.; Hadi, A.S.; Sakari, M. Relationship between awareness, knowledge and attitudes towards environmental education among secondary school students in Malaysia. World Appl. Sci. J. 2013, 22, 1326-1333.

34. Petty, R.E.; Cacioppo, J.T. The elaboration likelihood model of persuasion. In Communication and Persuasion; Springer: New York, NY, USA, 1986.

35. Yadav, R.; Pathak, G.S. Young consumers' intention towards buying green products in a developing nation: Extending the theory of planned behavior. J. Clean. Prod. 2016, 135, 732-739. [CrossRef]

36. Mostafa, M. Antecedents of egyptian consumers' green purchase intentions. J. Int. Consum. Mark. 2006, 19, 97-126. [CrossRef]

37. Beck, L.; Ajzen, I. Predicting dishonest actions using the theory of planned behavior. J. Res. Pers. 1991, 25, 285-301. [CrossRef]

38. Tonglet, M.; Phillips, P.S.; Read, A.D. Using the theory of planned behaviour to investigate the determinants of recycling behaviour: A case study from Brixworth, UK. Resour. Conserv. Recycl. 2004, 41, 191-214. [CrossRef]

39. Ajzen, I.; Fishbein, M. Understanding Attitudes and Predicting Social Behaviour; Prentice-Hall: Boston, MA, USA, 1980.

40. Rhodes, R.E.; Courneya, K.S. Investigating multiple components of attitude, subjective norm, and perceived control: An examination of the theory of planned behaviour in the exercise domain. Br. J. Soc. Psychol. 2003, 42, 129-146. [CrossRef] [PubMed]

41. Oskamp, S.; Harrington, M.J.; Edwards, T.C.; Sherwood, D.L.; Okuda, S.M.; Swanson, D.C. Factors influencing household recycling behavior. Environ. Behav. 1991, 23, 494-519. [CrossRef]

42. Ajzen, I. Residual effects of past on later behavior: Habituation and reasoned action perspectives. Pers. Soc. Psychol. Rev. 2002, 6, 107-122. [CrossRef]

43. Schultz, W. Empathizing with nature: The effects of perspective taking on concern for environmental issues-statis. J. Soc. Issues 2002, 56, 391-406. [CrossRef]

44. Fishbein, M.; Ajzen, I. Belief, Attitude, Intention, and Behavior; AddisonWesley: Reading, MA, USA, 1975.

45. Liñán, F.; Rodríguez-Cohard, J.C.; Rueda-Cantuche, J.M. Factors affecting entrepreneurial intention levels. In Proceedings of the 45th Congress of the European Regional Science Association: Land Use and Water Management in a Sustainable Network Society, Amsterdam, The Netherlands, 23-27 August 2005.

46. Marques, C.S.; Ferreira, J.J.; Gomes, D.N.; Gouveia Rodrigues, R. Entrepreneurship education: How psychological, demographic and behavioural factors predict the entrepreneurial intention. Educ. Train. 2012, 54, 657-672. [CrossRef]

47. Prime Minister's Department. Government Transformation Programme Annual Report; Prime Minister's Department: Canberra, Australia, 2010. Available online: https://www.pemandu.gov.my/assets/ publications/annual-reports/GTP_2011_EN.pdf (accessed on 12 December 2017). 
48. Reinartz, W.; Haenlein, M.; Henseler, J. An empirical comparison of the efficacy of covariance-based and variance-based SEM. Int. J. Res. Mark. 2009, 26, 332-344. [CrossRef]

49. Cheung, R.; Lau, M.; Lam, A. Factors affecting consumer attitude towards organic food: An empirical study in Hong Kong. J. Glob. Sch. Mark. Sci. 2015, 25, 216-231. [CrossRef]

50. Walton, T.; Austin, D. Pro-environmental behavior in an urban social structural context. Soc. Spectr. 2011, 31, 260-287. [CrossRef]

51. Sánchez, M.; López-Mosquera, N.; Lera-López, F. Improving pro-environmental behaviours in spain. The role of attitudes and sociodemographic and political factors. J. Environ. Plan. Manag. 2015, 18, 47-66.

52. Podsakoff, P.M.; MacKenzie, S.B.; Lee, J.Y.; Podsakoff, N.P. Common method biases in behavioral research: A critical review of the literature and recommended remedies. J. Appl. Psychol. 2003, 88, 879-903. [CrossRef] [PubMed]

53. Harman, H.H. Modern Factor Analysis; University of Chicago Press: Chicago, IL, USA, 1976.

54. Bagozzi, R.P.; Yi, Y.; Phillips, L.W. Assessing construct validity in organizational research. Adm. Sci. Quart. 1991, 36, 421-458. [CrossRef]

55. Hair, J.F.; Ringle, C.M.; Sarstedt, M. PLS-SEM: Indeed a silver bullet. J. Mark. Theor. Pract. 2011, 19, $139-152$. [CrossRef]

56. Hair, J.F.; Ringle, C.M.; Sarstedt, M. Partial least squares structural equation modeling: Rigorous applications, better results and higher acceptance. Long Range Plan. 2013, 46, 1-12. [CrossRef]

57. Diamantopoulos, A.; Siguaw, J.A. Formative versus reflective indicators in organizational measure development: A comparison and empirical illustration. Br. J. Manag. 2006, 17, 263-282. [CrossRef]

(C) 2018 by the authors. Licensee MDPI, Basel, Switzerland. This article is an open access article distributed under the terms and conditions of the Creative Commons Attribution (CC BY) license (http:/ / creativecommons.org/licenses/by/4.0/). 